\title{
CLINICAL AND BIOCHEMICAL PROFILE OF OBESE AND OVERWEIGHT CHILDREN AT A TERTIARY CARE HOSPITAL.
}

1. FCPS (Pediatrics Medicine) Assistant Professor Pediatrics Unit-I Children Hospital Chandka Medical College/SMBBMU, Larkana.

2. MBBS, FCPS

Postgraduate Resident Pediatric Medicine

The Children's Hospital and The Institute of Child Health, Multan.

3. FCPS (Pediatrics Medicine) Assistant Professor Pediatrics Medicine Ghurki Trust Teaching Hospital, Lahore.

4. FCPS (Pediatrics Medicine) Senior Registrar Rai Medical College/ Doctor's Trust Teaching Hospital, Sargodha.

5. FCPS (Pediatrics Medicine) Fellow in Pediatrics Neurology Agha Khan Hospital, Karachi.

Correspondence Address:

Dr. Fazal Ur Rehman

Pediatric Medicine

The Children's Hospital and

The Institute of Child Health, Multan.

fazal171@gmail.com

Article received on:

18/07/2019

Accepted for publication:

10/10/2019

\section{INTRODUCTION}

Childhood and adolescent obesity is increasing especially in developing countries like Pakistan. It seem to affect most socio-economic classes as well as all ethnicities and geographies. ${ }^{1,2}$

Obesity is described as an abnormal growth of adipose tissue because of extension of fat cells size and / or an enlargement in their numbers. ${ }^{3}$ In 1998, obesity was labeled to be a global epidemic by WHO. ${ }^{4}$ The worldwide prevalence of childhood obesity marks a big difference amongst various regions of the world such as in US it affects about $30 \%$ childhood population to as low as $2 \%$ in African countries..$^{5-7}$ In Pakistan, the prevalence of childhood and adolescents with BMl > 25 are estimated to be around 3-6\% which is quite alarming. ${ }^{8}$ This age groups is most important considering that if not taken care these will go on to develop many chronic diseases in the later years of life. Many endocrine abnormalities, metabolic disorders as well as cardiovascular diseases are related to obesity. ${ }^{9}$ We planned to analyze the clinical and biochemical profile of obese as well as overweight children at a tertiary care hospital for the existence of metabolic syndrome (Met S).

\section{MATERIAL \& METHODS}

This cross sectional study was conducted at Department of Pediatrics Medicine, Children Hospital Chandka Medical College / Shaheed Mohtarma Benazir Bhutto Medical University, Larkana, from $1^{\text {st }}$ July 2018 to $31^{\text {st }}$ December 2018. Approval was granted from institutional ethical committee. 
All the children, aged 5 to 16 years, both gender, having $\mathrm{BMI}>85^{\text {th }}$ percentile regarding age and gender were enrolled. Consent was taken from parents/guardians of all the children taking part in this study. Convenient sampling technique was used for children attending Pediatric Outpatient Department of the institute. Children having genetic disorders, with diabetes, using medications for hypertension or lipid disorders were not included in the study.

Demographic characteristics along with history, lifestyle parameters and physical examination were noted for all the study participants. Height of all the participants was noted to the closest $0.1 \mathrm{~cm}$ with stadiometer. Weight was recorded to the closest $0.1 \mathrm{~kg}$, measured with electronic weighing scale. Waist circumference was taken as closest $0.1 \mathrm{~cm}$ at the midway level in between the lower rib margin and iliac crest while the study participant exhaling, using a measuring tape that was non-stretchable. Weight as kilograms divided by square of height in meters was taken as BMI whearas BMI more than 95th centile regarding age and gender was noted obese while BMI between 85th and 95th centile regarding age and gender was noted overweight. ${ }^{10}$ Blood sample was taken in the morning at a fasting state of 8 hours using venipuncture for biochemical parameters like fasting blood glucose, high density lipoprotein cholesterol (HDL-C), low density lipoprotein cholesterol (LDL-C), very low density cholesterol (VLDL-C) and triglycerides (TG). Abdominal ultrasound for the assessment of fatty liver was also done.

Metabolic syndrome (Met S) as described by the International Diabetes Federation (IDF) ${ }^{11}$ in children was evaluated if abdominal obesity (waist circumference more than or equal to $90^{\text {th }}$ percentile for age and sex) having 2 or more of these: 1) fasting TG more than or equal to 110 $\mathrm{mg} / \mathrm{dl}, 2) \mathrm{HDL}-\mathrm{C}$ less than or equal to $40 \mathrm{mg} /$ $\mathrm{dl}$, 3) blood Pressure more than or equal to $90^{\text {th }}$ percentile for age, gender and height centile, and 4) FBG more than or equal to $100 \mathrm{mg} / \mathrm{dl}$ were present. SPSS version 20 was used for data entry and analysis. Results were presented in terms of proportions, mean and standard deviations

\section{RESULTS}

A total of 78 cases were enrolled during the study period. There were 46 (58.9\%) male and $32(41.1 \%)$ female, with a male to female ratio of $1.4: 1$. Mean age amongst study participants was 10.8 years. We had $56(71.8 \%)$ children as overweight whereas 22 (28.2\%) obese.

Use of carbonated beverages (minimum 3 times a week) was noted in 50 (64.1\%). Bakery items usage (minimum 3 times a week) was noted in $68(87.2 \%)$. There were 18 (23.1\%) subjects who used to do exercise ( $>3$ times a week). There were 65 (83.3\%) participants who used to watch regular Television (minimum 1 hour daily) and $52(66.7 \%)$ with computer or mobile phone usage (minimum 1 hour per day). There were 44 (56.4\%) and 47 (60.2\%) participants who had a positive family history of diabetes mellitus and hypertension respectively.

Acanthosis nigricans was the most common entity seen in 55 (70.1\%) children during clinical examination, followed by hypertension 35 (44.9\%).

As far as laboratory findings of the study participants are concerned, mean $\pm S D$ of total cholesterol (mg/dl), TG (mg/dl), HDL-C (mg/dl), LDL-C $(\mathrm{mg} / \mathrm{dl})$, VLDL-C $(\mathrm{mg} / \mathrm{dl})$ and FBG were found to be $179.4 \pm 61.8,128.1 \pm 42.5,37.1$ $\pm 6.2,92.3 \pm 4.2,27.2 \pm 2.3$ and $87.8 \pm 3.2$ respectively.

It was noted that $30(38.4 \%)$ participants were having features of fatty liver and hepatomegaly as seen on abnormal abdominal ultrasound.

We noted 57 (73.1\%) subjects with hypercholesterolaemia, $\quad 31 \quad$ (39.7\%) hypertryglyceridaemia, 54 (69.2\%) with raised LDL-C, low HDL-C in 41 (52.6\%) whereas 11 (14.1\%) children were observed with raised fasting blood glucose levels.

Metabolic syndrome was found to be present in 31 (39.7\%) participants amongst which 18 were male and 13 female. Met $S$ was noted in 22 (70.9\%) children who were obese and 9 (29.1\%) 
overweight.

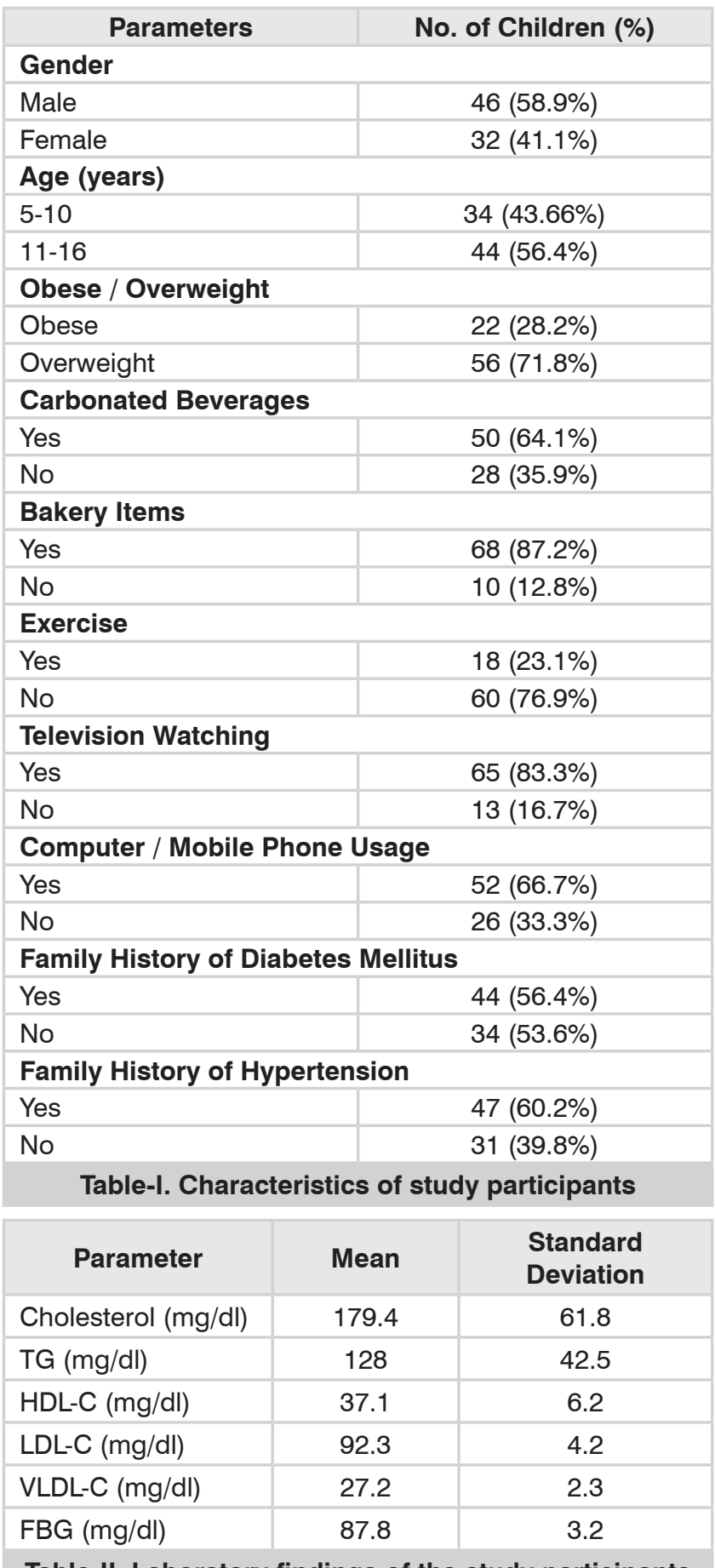

Table-II. Laboratory findings of the study participants

\section{DISCUSSION}

Big change in dietary patterns as well lifestyles are thought to be one of the main reasons for obesity that can further contribute to many diseases like insulin resistance, diabetes mellitus,
Met S, cardiovascular diseases in both adults and children. ${ }^{12-15}$ Recent data from around the world has clearly indicated a rising trend in childhood obesity especially in developing countries. Jafar $\mathrm{TH}$ et $\mathrm{al}^{8}$ found the prevalence of childhood obesity and overweight in Pakistan as 3\% from 1990-1994 and 5.7\% between 2004-2005 while studies from India noted that to be ranging between $2-12 \% .^{9}$ Unhealthy nutrition, physical inactivity, urbanization, socio-culture factors as well as traditional beliefs are contributing largely to this epidemic in our parts of the world. ${ }^{9}$

Prevalence of Met S varies amongst different age groups and populations. Cook $S$ and colleagues ${ }^{16}$ found Met $S$ to be present as $4 \%$ in age group of 12 to 19 years. The Bogalusa Heart Study ${ }^{17}$ conducted in age group of 8 to 17 years noted $3.6 \%$ participants to have Met S. High prevalence of Met $S$ has been noted in obese children in comparison as to non-obese and it seem to increasing with the increase in obesity. Met $S$ was found to be present in $39 \%$ of children with moderate obesity while this proportion went up to $50 \%$ in children who had severe obesity in a study comprising age group of 4-20 years. ${ }^{18}$ The findings of the present study were quite consistent with these studies and we found the prevalence of Met $S$ as $39.7 \%$ in the studied cases. A recent study from India ${ }^{19}$ found the prevalence of Met $S$ in obese and overweight children and adolescents as $32 \%$ which is also very close to what we noted. Cruz ML and coworkers ${ }^{20}$ recorded $29 \%$ of children with obesity to have Met S while $7 \%$ of overweight children to have Met S.

In the current study, we noted 57 (73.1\%) children to have hypercholesterolaemia which very close to another study done in India where they noted $72 \%$ obese and overweight children and adolescents to have hypercholesterolaemia. ${ }^{19}$ Other lipid profile findings were also very comparable to some other studies done similar study designs. ${ }^{18,21,22}$ In comparison to normal children, overweight children have been found to have raised $\mathrm{TG}$ and $\mathrm{HDL}-\mathrm{C}$ but comparable blood glucose levels. We noted mean \pm SD of total cholesterol $(\mathrm{mg} / \mathrm{dl})$, TG $(\mathrm{mg} / \mathrm{dl})$, HDL-C $(\mathrm{mg} /$ $\mathrm{dl})$, LDL-C (mg/dl), VLDL-C (mg/dl) and FBG 
were found to be $179.4 \pm 61.8,128.1 \pm 42.5$, $37.1 \pm 6.2,92.3 \pm 4.2,27.2 \pm 2.3$ and $87.8 \pm 3.2$ respectively. Other researchers from India ${ }^{19}$ and Bangladesh ${ }^{23}$ found very similar results.

Our study has few limitations as well as this was a cross sectional study where only overweight and children with obesity were considered. We did not evaluate any risk factors related to obesity.

Improving school based physical education, interventions involving large scale community based programs, encouraging parents to get more involved, safe routes of walking / bicycling to school, encouraging healthy eating, and regular health checkups as measures targeting childhood and adolescent population can certainly help bringing a change in pattern of obesity in the next few decades.

\section{CONCLUSION}

Met $S$ is not only limited to obese children as it can also affect children who are overweight. More studies involving multiple centers with bigger sample size can further verify the results of our findings.

\section{Copyright@ 10 Oct, 2019.}

\section{REFERENCES}

1. Chudasama RK, Eshwar T, Eshwar ST, Thakkar D. Prevalence of obesity and overweight among school children aged 8-18 years in Rajkot, Gujarat. Indian Pediatr 2016; 53(8):743-4.

2. Chandrasekhar T, Suchitra MM, Pallavi M, L N Srinivasa Rao P V, Sachan A. Risk factors for cardiovascular disease in obese children. Indian Pediatr 2017; 54(9):752-5.

3. Park K. Park's textbook of preventive and social medicine: 18th Edition, Banarsidas Bhanot Publishers, India, 2005.

4. WHO consultation on obesity. Special issues in the management of obesity in childhood and adolescence. In World Health Organization, ed. Obesity-preventing and managing the global epidemic. Geneva: WHO, 1998; 231-47.

5. Nuaim AR, Bamgboye EA, Herbish A. The pattern of growth and obesity in Saudi Arabian male school children. Int J Obesity Related Metabolic Disorders. 1996; 20:1000-5.
6. Suwan ML, Junjana C, Puetapaiboon A. Increasing obesity in school children in transitional society and the effect of the weight control programme. South East Asian J Tropical Med Public Health. 1993; 24:5904.

7. Ahmed M, Shah K, Kshirsagar VY. Prevalence and risk factor for obesity in urban and rural school going children of Karad Taluka, Maharashtra, India. Int J Contemp Pediatr. 2016; 3(4):1389-93.

8. Jafar TH, Qadri Z, Islam M, Hatcher J, Bhutta ZA, Chaturvedi N. Rise in childhood obesity with persistently high rates of undernutrition among urban schoolaged Indo-Asian children. Arch Dis Child 2008; 93:373-8.

9. Gupta N, Goel K, Shah P, Misra A. Childhood obesity in developing countries: Epidemiology, determinants, and prevention. Endocrine Reviews 2012; 33(1):48-70.

10. Gahagan S. Overweight and obesity. In: Kleigman Robert M, Stanton Bonita F, St. Geme Joseph W BRE, editors. Nelson Textbook of Pediatrics.2oth edn Elsevier Inc.; 2008. 179-188.

11. Parikh RM, Mohan V. Changing definitions of metabolic syndrome. Indian J Endocrinol Metab. 2012; 16(1):7-12.

12. Wasir JS, Misra A. The metabolic syndrome in Asian Indians: Impact of nutritional and socio-economic transition in India. Metab Syndr Relat Disord 2004; 2:14-23.

13. Misra A, Khurana L. Obesity and the metabolic syndrome in developing countries. J Clin Endocrinol Metab 2008; 93:S9-S30.

14. Chadha DS, Gupta N, Goel K, Pandey RM, Kondal D, Ganjoo RK, et al. Impact of obesity on the left ventricular functions and morphology of healthy Asian Indians. Metab Syndr Relat Disord 2009; 7:1518.

15. Goel K, Misra A, Vikram NK, Poddar P, Gupta N. Subcutaneous abdominal adipose tissue is associated with the metabolic syndrome in Asian Indians independent of intra-abdominal and total body fat. Heart 2010; 96:579-83.

16. Cook S, Weitzman M, Auinger P, Nguyen M, Dietz WH. Prevalence of a metabolic syndrome phenotype in adolescents: findings from the third National Health and Nutrition Examination Survey, 1988-1994. Arch Pediatr Adolesc Med. 2003; 157(8):821-7. 
17. Srinivasan SR, Myers L, Berenson GS. Predictability of childhood adiposity and insulin for developing insulin resistance syndrome (syndrome $X$ ) in young adulthood: The Bogalusa Heart Study. Diabetes. 2002; 51(1):204-9.

18. Weiss R, Dziura J, Burgert TS, Tamborlane W V., Taksali $\mathrm{SE}$, Yeckel CW, et al. Obesity and the metabolic syndrome in children and adolescents. $\mathrm{N}$ Engl $\mathrm{J}$ Med. 2004; 350(23):2362-74.

19. Santhosa, Rao S, Kamath N. Study of the clinical profile and biochemical parameters in overweight and obese children - a hospital based cross sectional study. Pak Pediatr J 2018; 42(2): 101-4.

20. Cruz ML, Weigensberg MJ, Huang TTK, Ball G, Shaibi $\mathrm{GQ}$, Goran MI. The metabolic syndrome in overweight hispanic youth and the role of insulin sensitivity. J Clin Endocrinol Metab. 2004; 89(1):108-13.
21. Liu W, Lin R, Liu A, Du L, Chen Q. Prevalence and association between obesity and metabolic syndrome among Chinese elementary school children: A school-based survey. BMC Public Health. 2010; 10(1):780-6.

22. Bustos P, Saez K, Gleisner A, Ulloa N, Calvo C, Asenjo $\mathrm{S}$. Metabolic syndrome in obese adolescents. Pediatr Diabetes. 2010; 11(1):55-60.

23. Mohsin F, Baki A, Nahar J, Akhtar S, Begum T, Azad K, et al. Prevalence of metabolic syndrome among obese children and adolescents. Birdem Med J 2011; 1(1): 21-25.

\begin{tabular}{|c|l|l|l|}
\hline \multicolumn{3}{|c|}{ AUTHORSHIP AND CONTRIBUTION DECLARATION } \\
\hline Sr. \# & \multicolumn{1}{|c|}{ Author(s) Full Name } & \multicolumn{1}{|c|}{ Contribution to the paper } & Author(s) Signature \\
\hline 1 & Asif Ali Khuhro & $\begin{array}{l}\text { Methodology, Data collection, } \\
\text { Proof reading. } \\
\text { Methodology, Literature review, }\end{array}$ \\
\hline 2 & Fazal Ur Rehman & $\begin{array}{l}\text { Data analysis, Drafting. } \\
\text { Methodology, Literature review, } \\
\text { Discussion. } \\
\text { Methodology, Literature review, }\end{array}$ \\
\hline 5 & Waqas Ali & $\begin{array}{l}\text { Najmi Usman } \\
\text { Discussion. } \\
\text { Methodology, Literature review, } \\
\text { Discussion. }\end{array}$ \\
\hline
\end{tabular}

